\title{
The Boudouard-Bell reaction analysis under high pressure conditions
}

\author{
Andrzej Mianowski - Zbigniew Robak • \\ Martyna Tomaszewicz $\cdot$ Sławomir Stelmach
}

CEEC-TAC1 Conference Special Issue

(C) The Author(s) 2012. This article is published with open access at Springerlink.com

\begin{tabular}{|c|c|c|}
\hline $\begin{array}{l}\text { Abstract A new method for the measurement of solid } \\
\text { fuel reactivity towards carbon dioxide has been developed. }\end{array}$ & $b_{1}, b_{2}, b_{3}$ & $\begin{array}{l}\text { Constants in L-H Eq. } 8 \text { related with kinetic } \\
\text { constants }\end{array}$ \\
\hline This new method takes into account high-pressure and & $B, B_{1}, B_{2}$ & Constants in Eqs. 12-13, 15, dimensionless \\
\hline temperature effects. Three devolatilized carbonaceous & & Constant in Eqs. $24,25, \mathrm{~K}^{-1} \mathrm{~s}^{-1}$ \\
\hline materials have been used in experiments: chars derived & $C, C_{1}, C_{2}$ & Constants \\
\hline $\begin{array}{l}\text { from lignite, bituminous coal and blast furnace coke. Pro- } \\
\text { cesses were carried out at temperatures of } 800,850 \text { and }\end{array}$ & {$\left[\mathrm{CO}_{2}\right],[\mathrm{CO}]$} & $\begin{array}{l}\text { Molar fractions of } \mathrm{CO}_{2} \text { and } \mathrm{CO} \text {, respec- } \\
\text { tively, } 0 \leq\left[\mathrm{CO}_{2}\right] \leq 1,0 \leq[\mathrm{CO}] \leq 1\end{array}$ \\
\hline $\begin{array}{l}900{ }^{\circ} \mathrm{C} \text { and pressures of } 1.52,2.5 \text { and } 3.4 \mathrm{MPa} \text {. Analysis of } \\
\text { the product gas composition was carried out with the }\end{array}$ & {$[\mathrm{CO}]_{\mathrm{m}}$} & $\begin{array}{l}\text { Maximum obtained molar fraction of } \mathrm{CO} \text {, } \\
0<[\mathrm{CO}] \leq 1\end{array}$ \\
\hline $\begin{array}{l}\text { maximum degree of conversion of } \mathrm{CO}_{2}\left(\alpha_{\mathrm{m}}\right) \text { proposed as a } \\
\text { representative reactivity parameter. Arrhenius and Eyring }\end{array}$ & DFE & $\begin{array}{l}\text { Distance from thermodynamic equilibrium, } \\
\text { dimensionless }\end{array}$ \\
\hline relationships have been analyzed, and values of the acti- & $E$ & Activation energy, $\mathrm{J} \mathrm{mol}^{-1}$ \\
\hline vation energy and activation volume have been calculated. & $k$ & $\begin{array}{l}\text { Rate coefficient, } \mathrm{s}^{-1} \text {, indexed constants } \\
\text { corresponds with adequate equations }\end{array}$ \\
\hline Keywords Boudouard-Bell reaction $\cdot \mathrm{CO}_{2} \cdot$ Gasification & $k_{\mathrm{g}}$ & Rate coefficient acc. to [23] \\
\hline reactivity $\cdot$ Kinetics $\cdot$ Temperature $\cdot$ Pressure & $K$ & $\begin{array}{l}\text { Equilibrium constant, calculated acc. to } \\
\text { Eq. 34, dimensionless }\end{array}$ \\
\hline List of symbols & $K_{\alpha}$ & Approximated equilibrium constant, \\
\hline Conversion degree of $\mathrm{CO}_{2}, 0<\alpha<1$ & & defined with (32), dimensionless \\
\hline Maximum obtained conversion degree of & $m$ & Mass of sample, $g$ \\
\hline $\mathrm{CO}_{2}$ during process, $0<\alpha_{\mathrm{m}} \leq 1$ & $m_{O}$ & Initial mass of sample, $\mathrm{g}$ \\
\hline $\begin{array}{l}\text { Conversion degree of solid phase of fuel, } \\
0 \leq \alpha_{\mathrm{s}} \leq 1\end{array}$ & $\dot{m}$ & $\begin{array}{l}\text { Mass flow of } \mathrm{CO}_{2} \text { in ambient temperature, } \\
\mathrm{g} \mathrm{s}^{-1} \text {, }\end{array}$ \\
\hline \multirow[t]{2}{*}{$A, A_{1}, A_{2}$} & $\eta$ & $\begin{array}{l}\text { Thermodynamic yield of process/reaction, } \\
0 \leq \eta \leq 1\end{array}$ \\
\hline & $\Delta v$ & $\begin{array}{l}\text { Sum of stoichiometric coefficients of } \\
\text { gaseous reactants }\end{array}$ \\
\hline \multirow{4}{*}{$\begin{array}{l}\text { A. Mianowski } \cdot \text { Z. Robak } \cdot \text { S. Stelmach } \\
\text { IChPW, Institute for Chemical Processing of Coal, } \\
\text { Zamkowa } 1 \text { Street, } 41-803 \text { Zabrze, Poland }\end{array}$} & $\begin{array}{l}P \\
D_{\Theta}\end{array}$ & Pressure of $\mathrm{CO}_{2}, \mathrm{MPa}$ \\
\hline & & Standard pressure $\sim 0.1 \mathrm{MPa}$ \\
\hline & $R$ & $8.314 \mathrm{~J} \mathrm{~mol}^{-1} \mathrm{~K}^{-1}$, gas constant \\
\hline & $\dot{R}$ & $\begin{array}{l}\text { Solid phase conversion rate, defined acc. to } \\
(5), s^{-1}\end{array}$ \\
\hline \multirow{3}{*}{$\begin{array}{l}\text { Department of Inorganic Chemistry, Technology and Fuels, } \\
\text { Silesian University of Technology, Krzywoustego } 6 \text { Street, } \\
\text { 44-100 Gliwice, Poland } \\
\text { e-mail: martyna.tomaszewicz@ @olsl.pl }\end{array}$} & $r^{2}$ & Determination coefficient, $0 \leq r^{2} \leq 1$ \\
\hline & $T_{0}$ & Ambient temperature, $\mathrm{K}$ \\
\hline & $T$ & Reaction/process temperature, $\mathrm{K}$ \\
\hline
\end{tabular}




$\begin{array}{ll}V & \text { Volume of particular reactant, } \mathrm{cm}^{3} \mathrm{~mol}^{-1} \\ \dot{V} & \text { Volumetric flow of } \mathrm{CO}_{2} \text { in ambient } \\ & \text { temperature, } \mathrm{cm}^{3} \mathrm{~s}^{-1}, \\ \Delta^{+} V & \text { Volume of activation, } \mathrm{cm}^{3} \mathrm{~mol}^{-1} \\ \tau & \text { Time, s } \\ \tau_{\mathrm{m}} & \text { Time to obtain maximum conversion of } \\ & \mathrm{CO}_{2}, \mathrm{~s}, \\ \tau_{0} & \text { Initial time in Eq. 12, h } \\ \tau_{z} & \text { Equivalent time, } \mathrm{s}\end{array}$

Subscripts

s, g Represents solid and gaseous phase, respectively

eq Equilibrium state

\section{Introduction}

A disproportionation reaction of carbon monoxide into carbon dioxide and carbon black was investigated at the end of XIX century, first by Sainte-Claire Deville in 1864 and then from $1869-1871$ by the English metallurgist Sir Isaac Lothian Bell [1]. As late as July 23rd, 1900, at a Paris conference, Octave Boudouard described and discussed his earlier published work [2] on the progress of the endothermic and reversible reaction:

$\mathrm{C}+\mathrm{CO}_{2} \rightleftarrows 2 \mathrm{CO} \quad \Delta H_{298}=172.5 \mathrm{~kJ} \mathrm{~mol}^{-1}$

which, in terminology of coal technology, is defined as carboxy reactivity.

Reaction (1) has seen many elaborations of its multi-subject aspects. In practice, a high carboxy reactivity results in undesirable characteristics of coke. This is because, when used in the blast furnace process and in the manufacturing of coal-graphite products, fuel consumption increases, its mechanical strength deteriorates, and the temperature of the process is reduced (the so-called "cooling down"). This detrimental effect (the excessively high carboxy reactivity) is also known and described in the processes of the industrial combustion of solid fuels, especially for coal. The reaction capacity of solid fuels dictates the possibility and method of their utilization. It is obvious that the low reactivity of blast furnaces and foundry cokes is desirable, while a higher reactivity of the fuel supplied to the gasification systems is preferred.

Carbon monoxide can be applied in many chemical synthesis reactions [3-8] including the following:

(1) the production of hydrogen in a homogenous WaterGas Shift reaction:

$\mathrm{CO}+\mathrm{H}_{2} \mathrm{O}^{(\mathrm{g})} \rightarrow \mathrm{CO}_{2}+\mathrm{H}_{2} \quad \Delta H_{298}=-41.1 \mathrm{~kJ} \mathrm{~mol}^{-1} ;$

(2) the synthesis of liquid motor fuels by the FischerTropsch process, both to produce gasoline and diesel oil as well as other chemical compounds and products like aldehydes and oxo alkohols obtained via hydroformylation;

(3) the synthesis of methanol $(1 \mathrm{~mol} \mathrm{CO}+2.2 \mathrm{~mol}$ $\mathrm{H}_{2}+$ addition of $\mathrm{CO}_{2}$ );

(4) the synthesis of dimethyl ether;

(5) the synthesis of acetic acid;

(6) the production of the chemical warfare agent phosgene with chlorine participation, which is forbidden but necessary to produce polyurethane foams;

(7) the production of sodium formate by means of reaction with sodium hydroxide;

(8) the production of the PHB (poly-3-hydroxybutyrate) biopolymer for use in the production of biodegradable packaging.

Furthermore, carbon monoxide is used in the environmentally important catalytic processes of the reduction of nitrogen oxide according to the reaction: $\mathrm{NO}+\mathrm{CO}=1 / 2 \mathrm{~N}_{2}+\mathrm{CO}_{2}$ [9].

The optimal situation is when the measure of reactivity is strictly connected to the kinetic constant of reaction (1). Most often however, it is assumed that the reaction under consideration can be expressed by simplifying but technologically sensible approximations, by the three kinetic constants:

$\mathrm{C}+\mathrm{CO}_{2} \underset{k_{-1}}{\stackrel{k_{1}}{\leftrightarrow}} \mathrm{CO} \uparrow+\mathrm{C}_{\mathrm{s}} \mathrm{O}$

$\mathrm{C}_{\mathrm{s}} \mathrm{O} \stackrel{k_{2}}{\longrightarrow} \mathrm{CO} \uparrow$

In this article, a new conception of Boudouard-Bell reaction analysis is proposed, using both our own and literature derived data, as well as a specially designed high-pressure experimental set-up. For reaction (1), from both a thermodynamic point of view and from the Le ChatelierBrauns principle $(\Delta v=2-1=+1)$, an increase in pressure results in a shift of the reaction equilibrium to the left (in the direction of the reactants); however, because of mechanism (3) and (4) as well as the different characteristics of the different carriers of carbon as compared to graphite, increased pressure sometimes aids the reaction.

The kinetics of the Boudouard-Bell reaction/process

The course of the heterophase reaction (1) is limited by many factors, including:

(1) thermodynamic parameters $(T, P, V)$;

(2) the quality of the carbon carrier that is dependent upon what fuel is used, which may include biomass (including waste), coal that has undergone either low or high levels of metamorphosis, chars, cokes and graphite only for cognitive purposes, as well as on the presence of mineral substances; and. 
(3) the means of the solid sample preparation (particle size reduction, porosity) and the type of process employed (stationary process, once-through process, fluidized process).

As a result, many kinetic equations for the reaction in question have been proposed; herein, only the most popular are presented. They can be grouped according to the presence of the solid phase, gas phase or of both phases. It is known that the factor hampering an explicit quantification of the reaction kinetics is a complex of carbon $(\mathrm{C})$ with the product $(\mathrm{CO})$, written in the mechanism reaction Eqs. 3 and 4 as $\mathrm{C}_{\mathrm{s}} \mathrm{O}$.

\section{Solid phase analysis}

The entire group of equations takes into account a loss of the solid phase, i.e., a loss of weight of the sample, represented by the level of conversion. By using the Arrhenius equation, the following expression can be derived [10-19]:

$$
\begin{gathered}
\dot{R}=\frac{d \alpha_{s}}{d \tau}=A \cdot \exp \left(-\frac{E}{R T}\right)\left(1-\alpha_{s}\right) \\
T=\text { const, } P=0.1 \mathrm{MPa}=\text { const }
\end{gathered}
$$

Solving Eq. 5 for the condition $\tau=0, \alpha_{\mathrm{s}}=0$ gives the typical first-order kinetic relationship:

$g\left(\alpha_{s}\right)=A \cdot \exp \left(-\frac{E}{R T}\right) \cdot \tau \quad$ where $g\left(\alpha_{s}\right)=-\ln \left(1-\alpha_{s}\right)$

The other form of the mass integral most often encountered is the $g\left(\alpha_{\mathrm{s}}\right)=1-\left(1-\alpha_{\mathrm{s}}\right)^{1 / 3}$ expression, according to the simplified Shrinking Core Model [20, 21].

\section{Gaseous phase analysis}

The Genevan method, based upon the work of Dahme and Junkers [22], is one of the most widespread methods for testing and determining the reactivity of cokes and chars against $\mathrm{CO}_{2}$, and it uses differential equations of the reaction kinetics involved in changes to the coke surface area. The Genevan method determines the reaction rate constant based upon the analysis of $\mathrm{CO}_{2}(\mathrm{CO})$ content in the product gas from the gasification of coke and chars by means of $\mathrm{CO}_{2}$ at a temperature of $1,000{ }^{\circ} \mathrm{C}$.

For the integral form of the kinetic equations expressed in [23], the kinetic (dependent) variable is the level of $\mathrm{CO}_{2}$ conversion:

$\alpha=\frac{1-\left[\mathrm{CO}_{2}\right]}{1+\left[\mathrm{CO}_{2}\right]}, \quad 0 \leq\left[\mathrm{CO}_{2}\right] \leq 1$

Formula (7) is valid for the gaseous phase, assuming other gases are not present, i.e., that the following identity holds:
$\left[\mathrm{CO}_{2}\right]+[\mathrm{CO}]=1$.

A final expression for the kinetic equation is:

$g(\alpha)=k_{\mathrm{g}} \frac{m_{0} T_{0}}{\dot{V} T}$

where the mass integral $g(\alpha)$ is expressed by:

$g(\alpha)=-\alpha-2 \ln (1-\alpha)$

The right side of the Eq. 10 is a linear combination of both the Ist (F1) and 0th (R1) kinetic orders using symbolic notation for the (2F1-R1) mechanisms. Equation (9) can be written in a general form:

$g(\alpha)=k \tau_{z}$

Based on the method described above, Słomska [24] has proposed another empirical formulation under the assumption of condition (8) that is comprised of 5 constants:

$$
\begin{aligned}
{[\mathrm{CO}] } & =B_{1} \exp \left[-k_{1}\left(\tau-\tau_{0}\right)\right]+B_{2} \exp \left[-k_{2}\left(\tau-\tau_{0}\right)\right], \tau_{o} \\
& =0.28 \mathrm{~h}=\text { const. }
\end{aligned}
$$

Analyses conducted by the authors (based on detailed data of Słomska given in [24]) have proved that, for the condition $\left(\tau-\tau_{\mathrm{o}}\right)=0$ and $[\mathrm{CO}]=0, B_{1}=B_{2}$, the resulting equation has the characteristic form of the consecutive reactions comprising the kinetic constants $k_{1} i k_{2}$ :

$[\mathrm{CO}]=B\left[\exp \left(-k_{1} \tau\right)-\exp \left(-k_{2} \tau\right)\right], k_{2}>k_{1}$.

The maximum amount of the $[\mathrm{CO}]_{\mathrm{m}}$ created derives from the condition $\frac{\mathrm{d}[\mathrm{CO}]}{\mathrm{d} \tau}=0$, i.e. for:

$\tau_{\mathrm{m}}=\frac{\ln \left(\frac{k_{2}}{k_{1}}\right)}{k_{2}-k_{1}}$ or $\quad \tau_{\mathrm{m}}=\frac{1}{k_{\mathrm{ln}}}$

where $k_{\ln }$ is the logarithmic mean of rate coefficients $k_{2}$ and $k_{1}$.

$[\mathrm{CO}]_{\mathrm{m}}=B\left[\left(\frac{k_{1}}{k_{2}}\right)^{\frac{k_{1}}{k_{2}-k_{1}}}-\left(\frac{k_{1}}{k_{2}}\right)^{\frac{k_{2}}{k_{2}-k_{1}}}\right]$.

Gaseous and solid phase conversion analysis

For the non-catalytic reaction according to the LangmuirHinshelwood $(\mathrm{L}-\mathrm{H})$ mechanism, the kinetic equation most often proposed is [25-27]:

$\dot{R}=\frac{b_{1}\left[\mathrm{CO}_{2}\right]}{1+b_{2}[\mathrm{CO}]+b_{3}\left[\mathrm{CO}_{2}\right]}$

Equation 16 depends on the conventions of the $\mathrm{L}-\mathrm{H}$ mechanism; however, in the general equation, it is assumed that $\left[\mathrm{CO}_{2}\right] \propto \mathrm{P}\left(\mathrm{CO}_{2}\right)$ and $[\mathrm{CO}] \propto \mathrm{P}(\mathrm{CO})$. The coefficients 
$b_{1}, b_{2}, b_{3}$ are rigorously connected to the kinetic rate constants, $k_{-1}$ and $k_{2}$ from Eqs. 3 and 4 . At the same time, the form of the expression on the left side of Eq. 16 is important because relations between coefficients $b_{2}$ and $b_{3}$ and the kinetic constants are the simplexes with the mathematical structure of the Arrhenius law [28].

$$
b_{2}=\frac{k_{-1}}{k_{2}}=A_{1} \exp \left(\frac{\Delta E_{1}}{R T}\right) \quad b_{3}=\frac{k_{1}}{k_{2}}=A_{2} \exp \left(\frac{\Delta E_{2}}{R T}\right)
$$

As a result, differences in activation energy $(\Delta E)$ are used. Often these have positive values that, in a notation of $\exp (\Delta E / R T)$, can result in a misunderstanding (a negative value of activation energy). Using relation (17) and satisfying condition (8), one can derive the linear form:

$\frac{1}{\dot{R}}=\frac{1+b_{2}}{b_{1}} \frac{1}{\left[\mathrm{CO}_{2}\right]}+\frac{b_{3}-b_{2}}{b_{1}}$

No results were found in the literature that could confirm the validity of (18) over the entire range of $\mathrm{CO}_{2}$ content variability, $0<\left[\mathrm{CO}_{2}\right] \leq 1$, without additional simplifications.

\section{Materials and methods}

A series of tests on the influence of pressure on the course of the Boudouard-Bell reaction for the chars from the selected Polish coal (bituminous and lignite) and coke were conducted in a prototype laboratory research stand designed in accordance with our own concept and constructed at the Institute for Chemical Processing of Coal in Zabrze (Fig. 1). The stand has been used to determine the fuels' reactivity in conditions of elevated pressure as high as $5 \mathrm{MPa}$.

Carbon dioxide is supplied from the bottle through a reduction valve (1) at the established flowrate, set by means of the controller (3), to the pressure pipe reactor (6) placed vertically in an electric oven (4). In the initial zone of the reactor (6), filled in with the ceramic balls to increase thermal capacity of the system, carbon dioxide is heated up to the required temperature. Afterwards it is transferred to the reaction zone where the cylinder barrel (5) is placed. The cylinder contains an precisely weighed sample of the char. The product gas leaving reactor flows through the pipe cooler (7), where the gases are cooled down, and then flows through the pressure regulation system (3), which also constitutes the pressure expansion system. After the cooling down process and pressure expansion, the product gas is directed to the on-line connected gas analyzer that measures concentrations of $\mathrm{CO}, \mathrm{CO}_{2}$ and $\mathrm{O}_{2}(\mathrm{~S}-700$ of the SICK company). Process data (temperature, pressure, composition of the product gases) are gathered in a data acquisition system with the possibility for export into an Excel spreadsheet.

The procedure of measuring the reactivity of coal or char in conditions of elevated pressure by means of the above-described research stand is as follows:

- procurement of the char of the tested coal in accordance with the procedure accepted in IChPW that comprises a temperature program and corresponds to the flow rates of the inert gas during pyrolysis;

- pumping of carbon dioxide at an increased flowrate (in relation to the rate applied during process) through the cold sample bed to evacuate the air until the oxygen concentration drops below $1 \%$;
Fig. 1 Scheme of the research stand for testing the reactivity of carbon-containing materials towards $\mathrm{CO}_{2}$ under elevated pressure

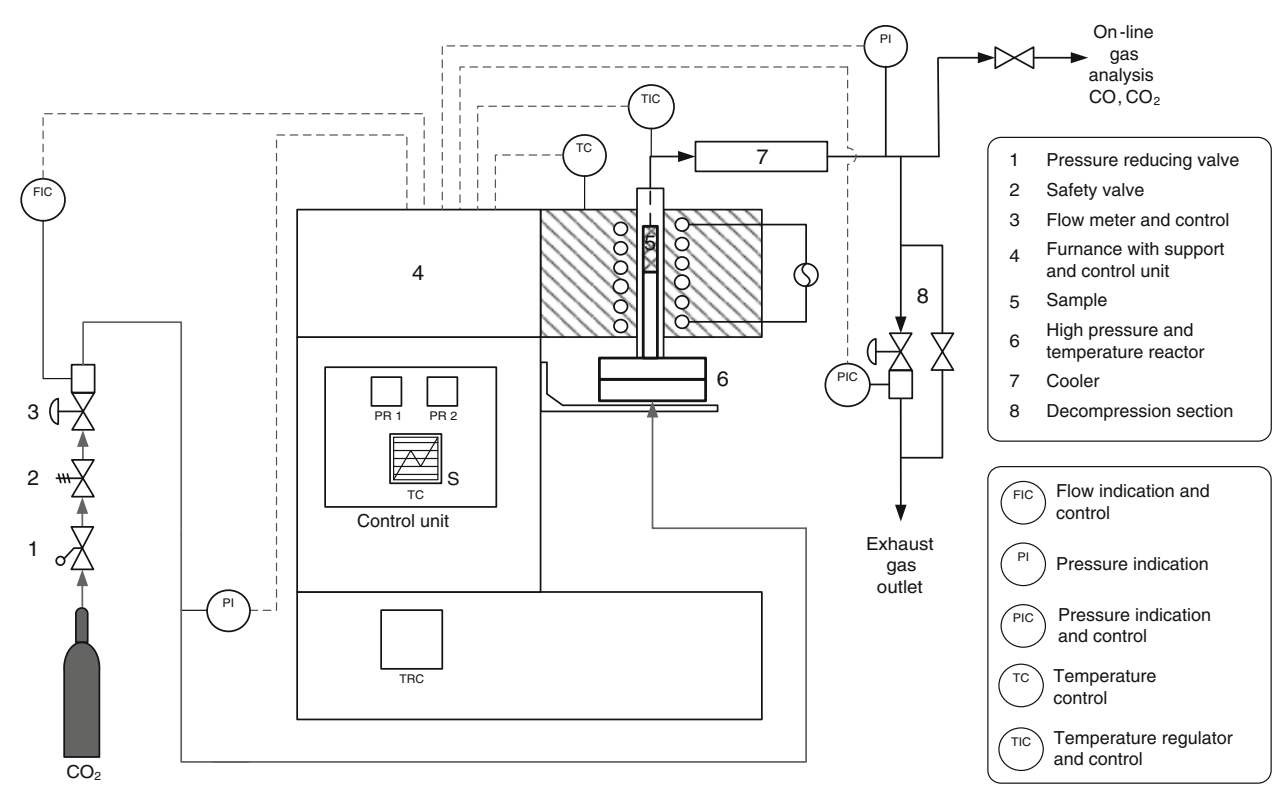


Table 1 Proximate analysis of the carbonaceous materials used

\begin{tabular}{lcrrrr}
\hline Parameter & \multicolumn{4}{l}{ Sample (coals were classified by rank) } & \\
\cline { 2 - 6 } & Lignite B & LigB char & hvCb coal & hvCb coal char & Coke \\
\hline Moisture, air dried basis/\% & 9.0 & 1.0 & 4.3 & 1.2 & 0.9 \\
Ash, dry basis/\% & 27.9 & 42.4 & 8.9 & 3.8 & 1.3 \\
Volatile matter, dry and ash free basis/\% & 60.8 & 2.5 & 38.7 & 1.3 \\
\hline
\end{tabular}

- $\quad$ setting of the established $\mathrm{CO}_{2}$ flow and pressure during measurement (of the reactivity) and switching on the oven to reach the assumed test conditions; and.

- observation of concentration changes of $\mathrm{CO}$ and $\mathrm{CO}_{2}$ after the final, assumed test temperature is reached until the readings of the analyzer stabilize on one level (with a deviation of up to $\pm 3 \%$ ), approximately $30-45 \mathrm{~min}$ after the temperature of the test has been reached.

For the studies, two chars obtained by devolatilization of lignite and bituminous coal were used as well as one sample of coke. Lignite and bituminous coal samples were derived from Polish mines. The coke was produced in a Polish coke plant and is used industrially in blast furnaces. Proximate analysis of the materials used is given in Table 1.

Experiments were performed according to following conditions:

- $6 \mathrm{~g}$ sample mass was used in every test run,

- the $\mathrm{CO}_{2}$ mass flow was set to $22 \mathrm{~g} \mathrm{~h}^{-1}$,

- the particle size of the chars and coke samples ranged from 1 to $3.15 \mathrm{~mm}$,

- the $\mathrm{CO}_{2}$ pressure employed was 1.52, 2.50 and 3.40 MPa and

- the temperatures were 800,850 and $900{ }^{\circ} \mathrm{C}$.

\section{Results and discussion}

Kinetic models (5), (6), (11) and (13) have been presented in typical categories, i.e., according to the level of changes of the solid phase $\left(\alpha_{\mathrm{s}}\right)$ or of $\mathrm{CO}_{2}(\alpha)$ or share of the gas phase constituents $\left([\mathrm{CO}],\left[\mathrm{CO}_{2}\right]\right)$ with time. The research presented was intended for another objective because the authors were interested in the influence of pressure on the gasification process by means of $\mathrm{CO}_{2}$. The installation in which the research was conducted allows only for analysis of the gaseous phase without the possibility to register mass reduction of the solid phase.

For consideration of the reaction in question, Eq. 11 and 13 were used. Taking into account Eq. 11, it was assumed that the maximum amount of carbon monoxide
$[\mathrm{CO}]=[\mathrm{CO}]_{\mathrm{m}} \leq 1$ can be produced. This corresponds to a maximum level of conversion $\alpha_{\mathrm{m}}$.

Changes in the volume fraction of $\mathrm{CO}$ during $\mathrm{CO}_{2}$ gasification of coke samples at temperatures of 800,850 and $900{ }^{\circ} \mathrm{C}$ are presented in Fig. 2a, b and c for processes carried out under pressure of $1.52,2.5$ and $3.4 \mathrm{MPa}$, respectively. The maximum content of $\mathrm{CO}$ in the product gas increases with temperature, especially for processes performed at the lowest pressure of $1.52 \mathrm{MPa}$.

To determine the reactivity of coals under elevated pressure (isothermal-isobaric conditions) the equivalent time is constant (independent of temperature):

$\tau_{z}=\frac{\mathrm{m}}{\dot{\mathrm{m}}}=C \cong \mathrm{const}$

And, in accordance with the isokinetic effect [29] and as was presented earlier [30] for several mechanisms: F1, R1, R2, R3 and for small levels of conversion the left side of the Eq. 11 can be presented in the simplest form of 0th kinetics and, where $\alpha-2 \ln (1-\alpha) \cong \alpha$ :

$g(\alpha)=\alpha$

Substituting Eqs. 19 and 20 into 11, the following equation can be formulated, where the kinetic constant $k$ has been expressed in the classic Arrhenius relation:

$\alpha=k \frac{\mathrm{m}}{\dot{\mathrm{m}}}=C k=C A e^{\frac{-E}{R T}}$

Taking the natural log of both sides of Eq. 21, the function takes the linear form:

$\ln \alpha=\ln (C A)-\frac{E}{R T}$

For the coordinate $\alpha=\alpha_{\mathrm{m}}$ and the conditions of the experiment, Eq. 23 becomes a measure of the fuel's reactivity

$\ln \alpha_{m}=C_{1}-\frac{E}{R T}, \quad P=\mathrm{const}$

Equation 23 shows that, for each temperature $\mathrm{T}$ there is a corresponding maximum level of conversion of $\mathrm{CO}_{2}$. In turn, for $T=$ const and varying $P=$ var, the Eyring's equation was used [29, 31] in a form as in [32]: 

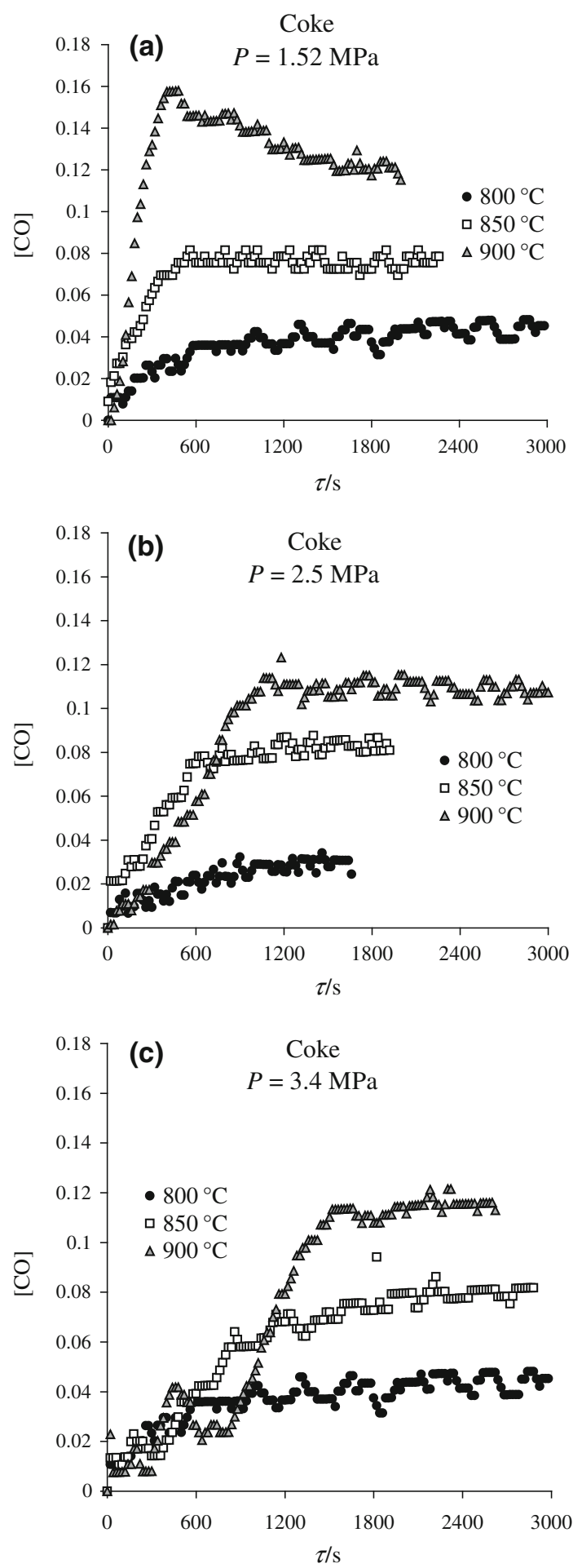

Fig. 2 Changes of $\mathrm{CO}$ content in the product gas during $\mathrm{CO}_{2}$ gasification of coke at different temperatures for pressures of 1.52 (a), 2.5 (b) and $3.4 \mathrm{MPa}(\mathbf{c})$

$k=C_{0} T \exp \left(-\frac{\Delta^{+} G}{R T}\right)$

where $\mathrm{C}_{0}$ is ratio of the Boltzmann constant (in $\mathrm{J} \mathrm{K}^{-1}$ ) to the Planck constant (in $\mathrm{J} s$ ) and amounts to
$\mathrm{C}_{0}=0.2084 \times 10^{11} \mathrm{~K}^{-1} \mathrm{~s}^{-1}$. Equation 24 can be rewritten as:

$\ln k=\ln \left(C_{0} T\right)-\frac{\Delta^{+} G}{R T}$

since: $\frac{\mathrm{d}\left(\Delta^{+} G\right)}{\mathrm{d} P}=\Delta^{+} V$

After differentiating (25) against pressure and using formula (26), the following expression results:

$\frac{\mathrm{d} \ln k}{\mathrm{~d} P}=-\frac{\Delta^{+} V}{R T}, \quad T=\mathrm{const}$

Based on expression (21) and for the coordinate $\alpha=\alpha_{\mathrm{m}}$ Eq. 27 will also be valid by substitution of $k$ by $\alpha_{\mathrm{m}}$ :

$\frac{\mathrm{d} \ln \alpha_{m}}{\mathrm{~d} P}=-\frac{\Delta^{+} V}{R T}, \quad T=\mathrm{const}$

From Eq. 28 a second linear dependence on pressure of the maximal $\mathrm{CO}_{2}$ conversion is obtained. The slope of this line is $-\Delta^{+} V / R T$, from which the activation volume can be derived:

$\ln \alpha_{\mathrm{m}}=\frac{-\Delta^{+} V}{R T} P+C_{2}, \quad T=\mathrm{const}$

The notation of (29) is based on Eq. 9, and it means that the 'nature' of $\alpha_{\mathrm{m}}$ is connected with constant $\mathrm{k}_{\mathrm{g}}$. Similarly, constants $k_{1}, k_{-1}$ and $k_{2}$, according to Eqs. 3, 4, 12-15 and 17,18 , are dependent on the gasification mechanism. This means that it is possible to evaluate the kinetic effect of the degree of conversion of $\mathrm{CO}_{2}$ without investigating the exact products (the ratio of $\mathrm{CO}$ to $\mathrm{C}_{\mathrm{s}} \mathrm{O}$ ). Comparing Eqs. 23 and 29, some commutation is noticed, resulting in the potential to analyze phenomena in a planned manner with a $[T \times P]$ experimental matrix for $3 \times 3$ experiments:

$\ln \alpha_{\max }$ versus $1 / T$, when $P=$ const,

$\ln \alpha_{\max }$ versus $P$, when $T=$ const.

The following outcomes may result:

(a) there may be no effect from pressure, $\alpha_{\mathrm{m}}=\mathrm{idem}$;

(b) there may be a positive effect of pressure, $\alpha_{m} \uparrow$ when $P \uparrow$;

(c) there may be a negative effect of pressure, consistent with thermodynamics, $\alpha_{\mathrm{m}} \downarrow$ when $P \uparrow$; or.

(d) there may be a combined effect, typical for (a) to (c).

Taking the matter further, as different possibilities for evaluating the reactivity of the solid fuels according to reaction (1) exist, in the discussed procedures both preparation and measurement (both of which are of significant importance) as the quantitative measure of the reactivity of coal against $\mathrm{CO}_{2}$, the thermodynamic rate of reaction was determined according to Szarawara [33]: 
$\eta=\frac{\alpha_{\mathrm{m}}}{\alpha_{\mathrm{eq}}} \quad T, P=\mathrm{const}$

Values of $\alpha_{\mathrm{m}}$ and $\eta$, representing tests carried out for every sample at different pressures and temperatures are presented in Table 2. Thermodynamic yield can be used in direct calculation of DFE, the distance from equilibrium, according to Eq. 31. DFE can represent the reactivity of solid fuels as well as $\alpha_{\mathrm{m}}$ :

$\mathrm{DFE}=1-\eta$

DFE and $\eta$ refers to hexagonal graphite.

Calculated distances from equilibrium are also given in Table 2. To establish $\alpha_{\text {eq }}$, in accordance with thermodynamic principles, the relations between chemical equilibrium constants and temperature and pressure are utilized:

$K_{\alpha}=K\left(\frac{P^{\Theta}}{P}\right)^{\Delta v}$, for reaction $(1) \Delta v=1$

and separate elements of it can be expressed in a following form:

- for constant $K_{x}$ expressed by the level of $\mathrm{CO}_{2}$ conversion [33]:

$K_{\alpha}=\frac{4 \alpha_{\mathrm{eq}}^{2}}{1-\alpha_{\mathrm{eq}}^{2}}$

- for the thermodynamic constant $K$ (from tables of Barin [34]), the following dependence was developed:

$$
\begin{aligned}
K & =\exp \left(\frac{-20780,9}{T}+20,32\right) \\
& =\exp (L), 298,15 \leq T \leq 1400 \mathrm{~K}
\end{aligned}
$$

and substituting (31) and (32) to Eq. 30 one can obtain: $\alpha_{\mathrm{eq}}=\left(\frac{\exp (L)}{4\left(\frac{P}{P^{\Theta}}\right)+\exp (L)}\right)^{1 / 2}$

As can be seen from Fig. 3, there exists a significant diversification in the obtained figures for the maximum conversion of carbon dioxide, which translates directly from the values received from the analysis of Eqs. 23 and 29.

The approximate values of activation energy were estimated by means of analysis of the Eq. 23 for the chars samples from lignite, bituminous coal and coke. As illustrated in Fig. 3a, $\mathrm{c}$ and e, the change in the $\mathrm{CO}_{2}$ conversion level with the increase of temperature is fully consistent with thermodynamics (an increase in $\mathrm{CO}_{2}$ conversion). The results are given in Table 3. Despite the fact that some simplification was performed, the results obtained are in good agreement with literature data [16, 22, 27, 35].

The impact of pressure on the level of the $\mathrm{CO}_{2}$ conversion has been investigated by analyzing Eq. 29 and obtaining values of the activation volume for the given temperature. For the gasification process of the lignite char at a temperature of $800{ }^{\circ} \mathrm{C}$ (Fig. 3b), the mixed influence of the pressure on $\alpha_{\mathrm{m}}$ can be observed. For higher temperatures, 850 and $900{ }^{\circ} \mathrm{C}$, dependence of $\alpha_{\mathrm{m}}$ on the pressure decreases and increases, respectively. Conversion level of carbon dioxide did not change for the processes run at a temperature of $800{ }^{\circ} \mathrm{C}$ when using bituminous coal chars (Fig. 3d). A similar dependence is observed for a temperature of $900{ }^{\circ} \mathrm{C}$. In the case of $850{ }^{\circ} \mathrm{C}$, however, the increase in pressure influences the level of $\mathrm{CO}_{2}$ conversion (i.e., it increases it). In the case of coke, a drop in the $\alpha_{m}$ value was observed with a pressure rise (Fig. 3f). An inverse relationship is observed for temperature of $850{ }^{\circ} \mathrm{C}$. The calculated values of the activation volumes are given

\begin{tabular}{|c|c|c|c|c|c|c|c|c|c|}
\hline \multirow{2}{*}{$\begin{array}{l}\text { Sample } \\
\text { Pressure/MPa }\end{array}$} & \multicolumn{3}{|c|}{ LigB char } & \multicolumn{3}{|c|}{ hvCb char } & \multicolumn{3}{|l|}{ Coke } \\
\hline & $800{ }^{\circ} \mathrm{C}$ & $850{ }^{\circ} \mathrm{C}$ & $900{ }^{\circ} \mathrm{C}$ & $800{ }^{\circ} \mathrm{C}$ & $850{ }^{\circ} \mathrm{C}$ & $900{ }^{\circ} \mathrm{C}$ & $800{ }^{\circ} \mathrm{C}$ & $850{ }^{\circ} \mathrm{C}$ & $900{ }^{\circ} \mathrm{C}$ \\
\hline \multicolumn{10}{|c|}{ Maximum fractional conversion of $\mathrm{CO}_{2}, \alpha_{\mathrm{m}}$} \\
\hline 1.52 & 0.151 & 0.249 & 0.354 & 0.01 & 0.019 & 0.075 & 0.019 & 0.035 & 0.091 \\
\hline 2.5 & 0.112 & 0.234 & 0.393 & 0.01 & 0.026 & 0.068 & 0.016 & 0.035 & 0.063 \\
\hline 3.4 & 0.153 & 0.239 & 0.359 & 0.01 & 0.024 & 0.075 & 0.015 & 0.036 & 0.060 \\
\hline \multicolumn{10}{|c|}{ Thermodynamic yield, $\eta$} \\
\hline 1.52 & 0.472 & 0.541 & 0.580 & 0.031 & 0.040 & 0.121 & 0.059 & 0.074 & 0.147 \\
\hline 2.5 & 0.431 & 0.616 & 0.756 & 0.038 & 0.068 & 0.131 & 0.062 & 0.092 & 0.121 \\
\hline 3.4 & 0.665 & 0.703 & 0.764 & 0.045 & 0.073 & 0.163 & 0.065 & 0.106 & 0.128 \\
\hline \multicolumn{10}{|c|}{ Distance from thermodynamic equilibrium, DFE } \\
\hline 1.52 & 0.528 & 0.459 & 0.420 & 0.969 & 0.960 & 0.879 & 0.941 & 0.926 & 0.853 \\
\hline 2.5 & 0.569 & 0.384 & 0.244 & 0.962 & 0.932 & 0.869 & 0.938 & 0.908 & 0.879 \\
\hline 3.4 & 0.335 & 0.297 & 0.236 & 0.955 & 0.927 & 0.837 & 0.935 & 0.894 & 0.872 \\
\hline
\end{tabular}

Table 2 Values of calculated reactivity parameters for studied samples 
Fig. 3 a, c, e Arrhenius relation (22) parameters determined for experiments performed at pressures of 1.52, 2.5 and 3.3 MPa for LigB char, hvCb char and coke, respectively; b, d, f Eyring model (29) fit to experimental data obtained at temperatures of 800,850 and $900{ }^{\circ} \mathrm{C}$ for $\mathrm{LigB}$ char, hvCb char and coke
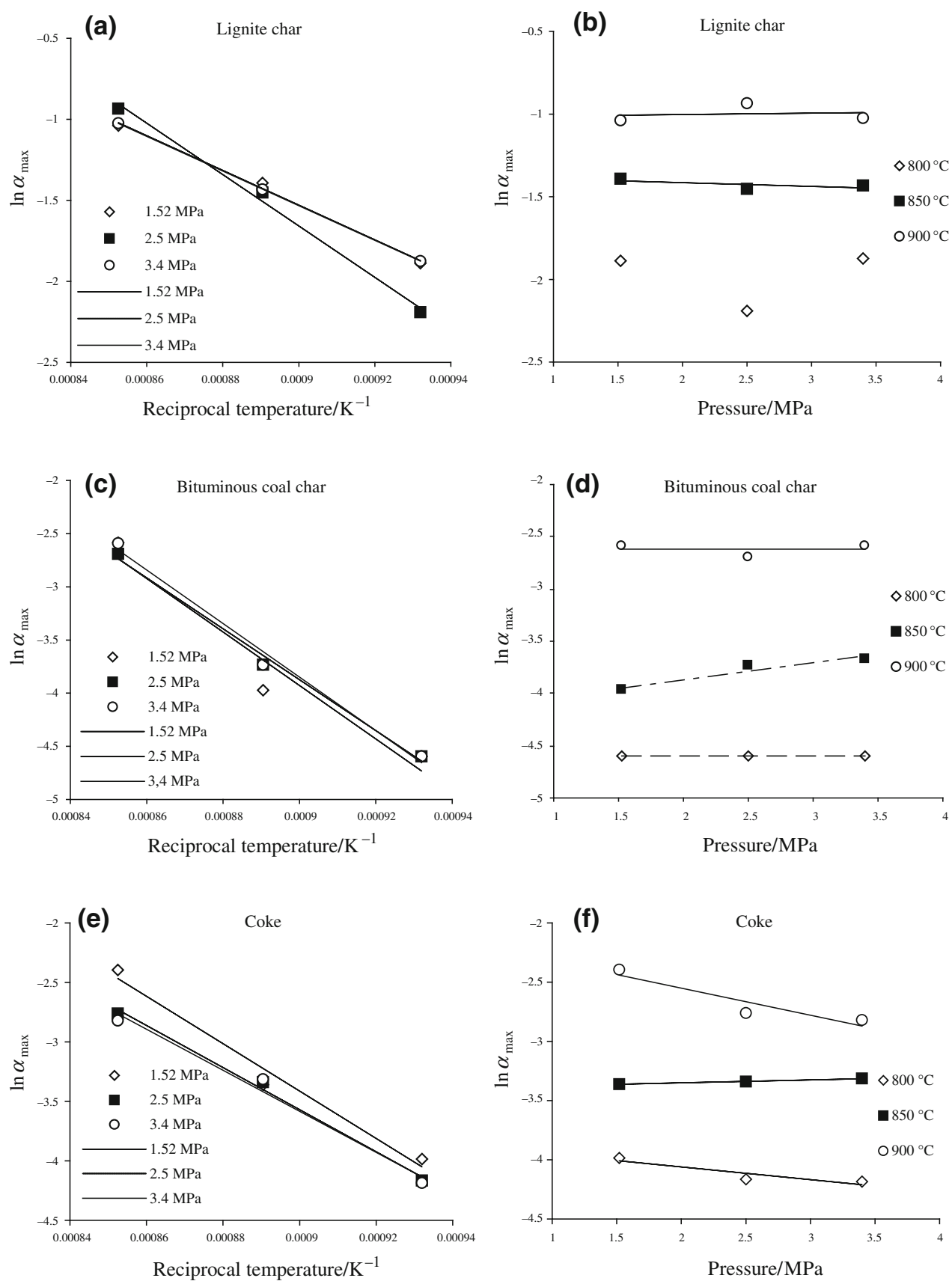

Table 3 Calculated activation energies of the $\mathrm{CO}_{2}$ gasification of samples under applied pressure conditions

\begin{tabular}{llrl}
\hline P/MPa & $\begin{array}{l}\text { hvCb char } \\
E / \mathrm{kJ} \mathrm{mol}^{-1}\end{array}$ & LigB char & Coke \\
\hline 1.52 & 208.9 & 89.0 & 165.8 \\
2.5 & 198.8 & 131.7 & 147.2 \\
3.4 & 209.2 & 88.9 & 143.3 \\
\hline
\end{tabular}

in Table 4. As one can observe, these values have a wide range. When compared to the values that are characteristic for the organic pressure reactions run in the liquid phase
Table 4 Calculated volume of activation of the $\mathrm{CO}_{2}$ gasification of studied samples at given temperature

\begin{tabular}{lccr}
\hline Temperature $/{ }^{\circ} \mathrm{C}$ & $\begin{array}{l}\text { hvCb char } \\
\Delta^{+} V / \mathrm{cm}^{3} \mathrm{~mol}^{-1}\end{array}$ & LigB char & Coke \\
\hline 800 & 0 & $\begin{array}{c}\text { Estimation } \\
\text { insufficient }\end{array}$ & 1061.9 \\
850 & & 227.5 & -258.9 \\
900 & -1538.7 & -113.6 & 247.1 \\
\hline
\end{tabular}

$\left(-25 \pm 30 \mathrm{~cm}^{3} \mathrm{~mol}^{-1}\right.$ [29]) or with the processes of thermalpressure hydrogenation of coals $\left(-20 \pm-15 \mathrm{~cm}^{3} \mathrm{~mol}^{-1}[36]\right)$ and coal macerals $\left(-18 \pm 9 \mathrm{~cm}^{3} \mathrm{~mol}^{-1}\right.$ [37]) when using 
tetralin as the hydrogen donor solvent, the activation volumes seem to be incomparably high. It should be noted, however, that testing of the hydrogenation of coals and of their macerals was conducted at very high pressure conditions (up to $50 \mathrm{MPa})$ [36, 37].

Moreover, the functions with comparably high slope coefficients as observed in Fig. $2 b$, $d$ and $f$ it should be distinguished. This is the case for the sample of hvcb char gasified at $850{ }^{\circ} \mathrm{C}$ (a positive effect of pressure) and coke gasified in temperatures of 800 and $900{ }^{\circ} \mathrm{C}$ (a negative effect of pressure and consistent with thermodynamics). For other samples and employed process parameters, the pressure has no or very small influence on the fractional conversion of carbon dioxide.

\section{Overall observations}

In the experimental conditions for the reaction (1) and for the established state parameters, i.e., temperatures of $800-900{ }^{\circ} \mathrm{C}$ and pressure elevated to $3.4 \mathrm{MPa}$ a measure of the reactivity of the fuels is the maximum level of $\mathrm{CO}_{2}$ conversion (according to Eq. 7 ). For comparison, in the established conditions of $\mathrm{T}$ and $\mathrm{P}$, to evaluate this reactivity, an application of a thermodynamic yield of reaction/ process (30) (or in different version (31)) was proposed.

The reference points are formulae (33) and (34), which derive from the progressing of the Boudouard's reaction (1) in the equilibrium conditions for the hexagonal form of graphite. The range of the thermodynamic reaction/process rates that was obtained comprised a large range of values. In each case, the increase in the reaction rate with the rise in temperature was observed. As in majority of cases, the increase of the rate with the increase of pressure was observed, which is extremely interesting from a thermodynamic point of view. As one might expect, according to the applied scale of reactivity (in the established thermodynamic conditions), higher reactivity of the lignite chars as compared to bituminous coal chars was confirmed.

Two linear dependences, (23) and (29), constitute relations of varying possibility for making use of the experimental matrix type $[\mathrm{T} \times \mathrm{P}]$ according to functional scales:

$\ln \alpha_{\mathrm{m}}$ versus $1 / T, \quad$ when $P=\mathrm{const}$

and

$\ln \alpha_{\mathrm{m}}$ versus $P, \quad$ when $T=$ const.

As a result, one can generate the slopes for the linear latent functions, often with very low linear coefficients of determination [38].

From Eq. 23, one can determine the activation energy, and the values obtained are in compliance with the literature data $[16,24,27,35]$.
Analysis of Eq. 29 shows that the thermodynamically conformable behaviour occurs only for highly outgassed coke (that is more comparable to graphite than chars) at temperatures of 800 and $900{ }^{\circ} \mathrm{C}$. For a majority of processes performed the very low values of the slope in Eyring plot indicate that pressure has no influence on the conversion of carbon dioxide due to the Boudouard reaction when slightly devolatilized materials are used. Calculated values of $\Delta^{+} V$ turned out to be inconsistent, and either increasing or decreasing of $\alpha_{\mathrm{m}}$ with increasing pressure was observed. Assuming that maximum conversion degree of carbon dioxide, $\alpha_{\mathrm{m}}$ is a kinetically defined variable, in some questionable cases only the absolute value of $\Delta V$ is more appropriate. Very large differences in the values reported in literature indicate that further studies on this phenomenon should be conducted. Very high values of activation volume were estimated, in contrast to the values given in $[36,37]$, representing the effect of an unisolated and open reaction system where the heterogeneous gasification reaction of carbonaceous fuel with gaseous $\mathrm{CO}_{2}$ (under the applied temperature and pressure conditions) occurs.

\section{Conclusions}

1. Pressure is a very important factor in the technological processing of solid fuels because of the very different and variable characteristics of the solid carriers of carbon. Very often, a positive impact (of pressure) on gasification process was observed, according to relation (29). When the maximum level of conversion of $\mathrm{CO}_{2}\left(\alpha_{\mathrm{m}}\right)$ increases with the pressure, it implies that $\Delta^{+} \mathrm{V}<0$, i.e., that the volume of the active complex is lower than that of the gaseous substrate, and the beneficial effect of reducing the system volume takes place: $\mathrm{V}\left(\mathrm{CO}_{2}\right)>\mathrm{V}\left(\mathrm{C}_{\mathrm{s}} \mathrm{O}\right)$.

2. In accordance with the above-described observations, Eqs. 23 and 29 have been proposed as tests for the determination of reactivity against $\mathrm{CO}_{2}$ for all carbonized solid fuels. Eqs. 30 and 31, on the other hand, describe relations of maximum to equilibrium level of reacting out of $\mathrm{CO}_{2}$ in the applied temperature and pressure conditions for the hexagonal graphite. These data determine the capacity of reaction of the real samples and exhibit the distinct features of the industrial solid fuels in relation to the reference fuel sample, graphite.

3. Further research on solid fuels reactivity is necessary to determine the universality of the rate constants $k_{1}$, $k_{-1} i k_{2}$ in the Langmuir-Hinshelwood equation in thermal-pressure conditions for the test matrix $[T \times P]$, which, because of multiple expressions of the $\mathrm{L}-\mathrm{H}$ relation, can be regarded as a preliminary proposal for the search for relations proportional to $k_{1}$, 
$k_{-1} i k_{2}$ or to their combination. One can assume that the easily determined $\alpha_{\mathrm{m}}$ is a representative quantity in relation to (previously) established kinetic constants.

Acknowledgements This study was partly performed within a framework of the Strategic Programme: "Advanced Technologies for Energy Generation: Development of Coal Gasification Technology for High-Efficient Fuels Production and Energy Generation" part of Research Task No. 2.2.1: "Coal Gasification Kinetics with $\mathrm{CO}_{2}$ Utilization in This Process" funded from National Centre for Research and Development.

Open Access This article is distributed under the terms of the Creative Commons Attribution License which permits any use, distribution, and reproduction in any medium, provided the original author(s) and the source are credited.

\section{References}

1. Zawidzki J. O postępach chemii nieorganicznej w r.1901, Chemik Polski. 1902;21:488 (In Polish).

2. Boudouard O. Sur la decomposition de l'oxyde de carbone en presence des oxydesmetalliques. C R Acad Sci. 1899;128: 1522-5.

3. Eide LI, Bailey DW. Precombustion decarbonisation processes. Oil Gas Sci Technol. 2005;60:475-84.

4. Steynberg AP, Nel HG. Clean coal conversion options using Fischer-Tropsch technology. Fuel. 2004;83:765-70.

5. Skrzypek J, Słoczynski J, Ledakowicz S. Methanol synthesis, science and engineering. Warsaw: Polish Scientific Publishers; 1994.

6. Xia JC, Mao DS, Chen QL, Tang Y. One step synthesis of dimethyl ether from syngas with Fe-modified zeolite ZSM-5 as dehydration catalyst. Catal Lett. 2004;98:235-40.

7. George C. Carbon monoxide. In: Kirk-Othmer, editor. Encyclopedia of Chemical Technology. New York: Wiley; 2001.

8. Wölfle H, Kopacka H, Wurst K, Preishuber-Pflügl P, Bildstein B. On the way to biodegradable poly(hydroxybutyrate) from propylene oxide and carbon monoxide via $\beta$-butyrolactone: multisite catalysis with newly designed chiral indole-imino chromium(III) complexes. J Organomet Chem. 2009;694:2493-512.

9. Jiang $\mathrm{X}$, Huang $\mathrm{H}, \mathrm{Li} \mathrm{H}$, Zheng $\mathrm{X}$. Catalytic properties of $\mathrm{CuO} /$ $\mathrm{Ce}_{0.2} \mathrm{Ti}_{0.8} \mathrm{O}_{2}$ and $\mathrm{CuO} / \mathrm{Ce}_{0.5} \mathrm{Ti}_{0.5} \mathrm{O}_{2}$ in the $\mathrm{NO}+\mathrm{CO}$ reaction. Energy Fuels. 2010;24:261-6.

10. Kovacik G, Chambers A, Ozum B. $\mathrm{CO}_{2}$ gasification of two Alberta coal chars. Can J Chem Eng. 1991;69:811-5.

11. Hodge EM, Roberts DG, Harris DJ, Stubington JF. The significance of char morphology on the analysis of high-temperature char- $\mathrm{CO}_{2}$ gasification rates. Energy Fuels. 2010;24:100-7.

12. Murillo R, Navarro MV, Lopez JM, Aylon E, Callen MS, Garcia T, Mastral AM. Kinetic model comparison for waste tire char reaction with $\mathrm{CO}_{2}$. Ind Eng Chem Res. 2004;43:7786-7786.

13. Kodama T, Funatoh A, Shimizu K, Kitayama Y. Kinetics of metal oxide-catalyzed $\mathrm{CO}_{2}$ gasification of coal in a fluidized-bed reactor for solar thermochemical process. Energy Fuels. 2001;15: $1200-6$

14. Fermoso J, Stevanov C, Moghtaderi B, Arias B, Pevida C, Plaza MG, Rubiera F, Pis JJ. High-pressure gasification reactivity of biomass chars produced at different temperatures. J Anal Appl Pyrolysis. 2009;85:287-93.

15. Molina A, Mendragon F. Reactivity of coal gasification with steam and $\mathrm{CO}_{2}$. Fuel. 1998;77:1831-9.
16. Khalil R, Varnegyi G, Jaschke S, Gronli MG, Hustad J. $\mathrm{CO}_{2}$ gasification of biomass chars: a kinetic study. Energy Fuels. 2009;23:94-100.

17. Leth-Miller R, Jensen AD, Jensen J, Glarborg P, Jensen LM, Hansen PB, Jorgensen SB. Comparative study of reactivity to $\mathrm{CO}_{2}$ of cokes used in stone wool production. Fuel Process Technol. 2005;86:551-63.

18. Gomez-Barea A, Ollero P, Fernandez-Baco C. Diffusional effects in $\mathrm{CO}_{2}$ gasification experiments with single biomass char particles. 1. Experimental investigation. Energy Fuels. 2006;20: 2202-10.

19. Bhat A, Ram Bheemarasetti JV, Rajeswara Rao T. Kinetics of rice husk char gasification. Energy Convers Manag. 2001;42: 2061-9.

20. Agarwal AK, Sears JT. The coal char reaction with $\mathrm{CO}_{2}-\mathrm{CO}$ gas mixtures. Ind Eng Chem Process Des Dev. 1980;19:364-77.

21. Nowicki L, Antecka A, Bedyk T, Stolarek P, Ledakowicz S. The kinetics of gasification of char derived from sewage sludge. J Therm Anal Calorim. 2010. doi:10.1007/s10973-010-1032-1.

22. Dahme A, Junker HJ. Die Reaktivität von Koks gegen $\mathrm{CO}_{2} \mathrm{im}$ temperaturbereich $1000 \ldots 1200{ }^{\circ} \mathrm{C}$. Brennst Chem. 1955;36: 193-9. (In German).

23. Mianowski A. Chemometric analysis of kinetics of the solid fuel reactivity. Acta Montana, IRSM AS CR Series B. 2001;120: 23-38.

24. Słomska I. Criterion of the evaluation of coke reactivity in the presence of carbon dioxide. Scientific Bulletins of the Stanisław Staszic University of Mining and Metallurgy, No. 414, Cracow: AGH University of Science and Technology Press; 1973. (In Polish).

25. Koenig PC, Squires RG, Laurendeau NM. Evidence for two-site model of char gasification by carbon dioxide. Carbon. 1985;23:531-6.

26. Koenig PC, Squires RG, Laurendeau NM. Char gasification by carbon dioxide: further evidence for a two-site model. Fuel. 1986;65:412-6.

27. Calo JM, Perkins MT. A heterogeneous surface model for the "steady-state" kinetics of the Boudouard reaction. Carbon. 1987;25:395-407.

28. Maskill H. The Arrhenius equation. J Chem Educ. 1990;27:111-4.

29. Isaacs NS. Liquid phase high pressure chemistry. New York: Wiley; 1981.

30. Mianowski A. Thermal dissociation in dynamic conditions by modeling thermogravimetric curves using the logarithm of conversion degree. J Therm Anal Calorim. 2000;59:747-62.

31. House JE. Principles of chemical kinetics. 2nd ed. Amsterdam: Academic Press; 2007.

32. Bigda R, Mianowski A. Influence of heating rate on kinetic quantities of solid phase thermal decomposition. J Therm Anal Calorim. 2006;84:453-65.

33. Szarawara J. Termodynamika chemiczna stosowana. Warsaw: WNT; 2007. p. 405. (In Polish).

34. Barin I. Thermochemical data of pure substances. Weiheim: VCH Velagsgesellschaft; 1989.

35. Marchon B, Tysoe WT, Carrazza J, Hainemann H, Somorjani GA. Reactive and kinetic properties of carbon monoxide and carbon dioxide on a graphite surface. J Phys Chem. 1988;92:5744-9.

36. Pajak J, Socha $Ł$. Effects of pressure on the rate of hydrogen transfer from tetralin to different rank coals. Fuel Process Technol. 2002;77-78:131-6.

37. Pająk J, Socha L. Effects of pressure on hydrogen transfer from tetralin to coal macerals. Energy Fuels. 2005;19:348-52.

38. Mianowski A, Radko T. Estimation of the parameters describing the changes of conversion degree under polyisothermal conditions. J Therm Anal Calorim. 2000;60:91-6. 